\title{
A response to the U.S. anti-hunger movement's mantras: Deserving objects of assistance, daily (Pyrrhic) victories, and protracted states of emergency
}

\author{
Review by David V. Fazzino II* \\ Bloomsburg University of Pennsylvania
}

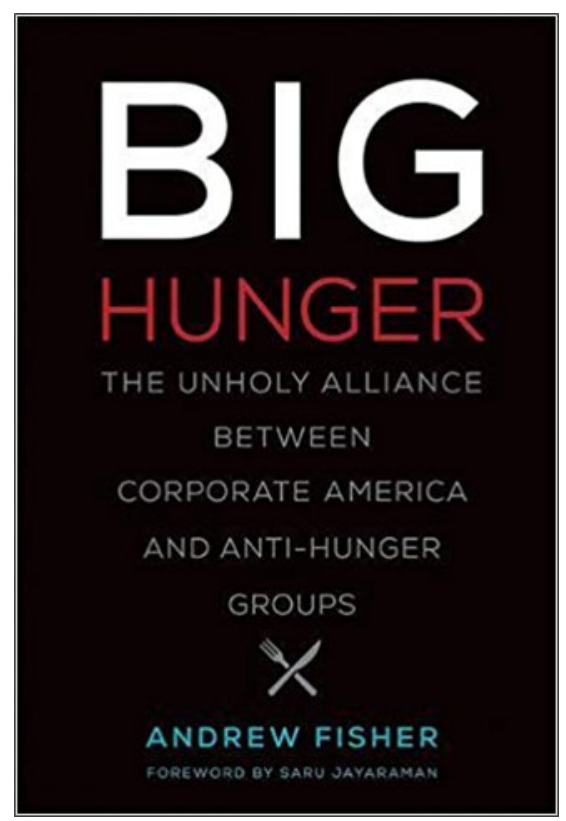

\begin{abstract}
Review of Big Hunger: The Unholy Alliance between Corporate America and Anti-Hunger Groups, by Andrew Fisher. (2017). Published by The MIT Press, Cambridge, Massachusetts. Available as hardcover and ebook; 360 pages. Publisher's website: https://mitpress.mit.edu/books/big-hunger
\end{abstract}

Submitted May 18, 2017 / Published online July 27, 2017

Citation: Fazzino, II, D. V. (2017). A response to the U.S. anti-hunger movement's mantras: Deserving objects of assistance, daily (Pyrrhic) victories, and protracted states of emergency [Book review]. Journal of Agriculture, Food Systems, and Community Development, 7(3), 217-219. http://dx.doi.org/10.5304/jafscd.2017.073.010

Copyright (C) 2017 by New Leaf Associates, Inc.

\begin{abstract}
A ndrew Fisher, a co-founder of the Commu1 nity Food Security Coalition, masterfully reveals the corporate collusion that dominates much of the anti-hunger movement in the United States, in a no-holds-barred account. In eight chapters he takes the reader on a journey through the depths of agreements that further disempower and stigmatize those on the margins of society. Fisher balances this with the hope that systematic

David Fazzino, assistant professor of anthropology at Bloomsburg University of Pennsylvania, is a cultural anthropologist trained in law and agro-ecology. His research interests include environmental anthropology, structural violence, intellectual property rights, food and energy policy, and medical anthropology. He can be reached at dfazzino@bloomu.edu; more details are at https://bloomu.academia.edu/DavidFazzino
\end{abstract}

change is already taking place in the form of individuals committed to uncovering the disenfranchising aspects of the anti-hunger industrial complex. He makes clear distinctions between anti-poverty and anti-hunger advocates, noting that their allegiances are split in a neoliberal era of governance in which the state continues to cut funding from assistance programs, allowing corporations such as Walmart to proliferate their own branded approach to battling hunger.

His extensive experience lays the groundwork for his policy recommendations, while his presentation of numerous case studies suggests that more just and robust community food systems are possible. Fisher maintains that issues of inequality must be addressed systemically in order to ensure 
that efforts to confront hunger do not do more harm than good by examining factors such as empty calorie consumption, low wages, and poor working conditions. Fisher blends his accounts of work in the field with news reports, policy analysis, personal communications, and survey data in order to explore competing visions for the direction of the anti-hunger movement. The business-as-usual model of "feeding the need" with corporate support (pp. 58-59) is contrasted with more innovative approaches that highlight the agency of those in need.

Fisher begins his introduction, "Lost Opportunities and Collateral Damage," with an account of the impacts of neoliberal policies and globalization on his hometown, Youngstown, Ohio. Youngstown is squarely in what has been dubbed the "Rust Belt," indicating its aging industrial infrastructure and overall economic decline, but as Fisher notes, “...rust is not an emergency. Rust does not happen in one day, but over a long period of time" (p. 4). Youngstown has problems, but its problems are not new. They do not constitute an emergency situation necessitating stopgap mechanisms of assistance; rather they are entrenched and systemic, requiring a paradigm shift.

The existing paradigm is thoroughly discussed in the first three chapters. Chapter 1, "Occupy Hunger," discusses the social construction of hunger and contrasts this with the concepts of food security and the right to food. Chapter 2, "The Charity Trap," considers collateral damage of the emergency food system. Fisher highlights the differences between social movements and the nonprofit sector, noting that increasing professionalization, narrow mission focus, and the need to build coalitions both across the food industry and outside it diminish the ability of large anti-hunger groups to see the trees for the forest. It is with these alliances that daily Pyrrhic victories over hunger are realized.

Chapter 3, "The Politics of Corporate Giving," describes the scope of, rationale for, and limitations imposed by corporate philanthropy in the realm of anti-hunger. Fisher unapologetically names corporations that have compiled a series of gaffs in their attempts to redeem and rebrand themselves for consumers. He points out corpora- tions that adopt philanthropic efforts see sizable returns on their investments through greater consumer appeal and greater economic resilience. In general, they institute policies of giving which give back to themselves through taxpayer-subsidized tax breaks and increasing consumer confidence in their brand. While claiming to support the communities of their employees and consumers through their philanthropic efforts, Fisher points out that they may also simultaneously work to systematically suppress wages and union organizing.

Chapter 4, "SNAP's Identity Crisis," 1 and chapter 5, "Economic Democracy through Federal Food Programs," address the contested nature of federal food policies (SNAP, USDA commodity purchases, and school meals) and their implications for the health, nutrition, and well-being of those who are deemed worthy of assistance. Chapter 6, "Who's at the Table Shapes What's on the Agen$\mathrm{da}$," discusses the relative absence of those who are poor from decision-making processes, as "all too often, the anti-hunger movement seeks to advocate for the poor instead of with them" (p. 209).

Although hunger is symptomatic of poverty, Fisher notes that many entities and individuals involved in the anti-hunger movement are unwilling or unable to address larger structural concerns. Their narrow focus leads them to a growthoriented model in which the goal is to get bigger in order to supply ever-larger quantities of food to more and more people. Success is measured through how much food is delivered, emphasizing quantity over quality. Work to scale up the infrastructure of food banks leads to viewing the buildings themselves as stakeholders in the process. This means that they must be fully utilized in order to justify the ask, the donations which made the structure possible in the first place. Similar to the privatized prison system that constantly seeks more and more offenders within a supply-demand framework to justify building more prisons (Parenti, 2000), the worthiness of the structure is defined through channeling ever more food out to the deserving poor. In both instances, those claiming

\footnotetext{
${ }^{1}$ SNAP (Supplemental Nutrition Assistance Program) is the federal food-purchasing assistance program for low- and noincome people.
} 
to defend the morality of society congratulate themselves and one another for having fought the good fight.

Despite Fisher observing a fractured food security system in the United States, he still maintains hope that collaboration is possible in the context of a more robust and inclusive federal food assistance program that prioritizes nutrition. $\mathrm{He}$ notes that those who work in anti-hunger and antipoverty ultimately share a concern for people who are hungry. He views SNAP as a key area where significant progress can be made. His hope rests on the notion that nonprofits that have adopted a growth model will be willing to work for the greater good. We could hope that corporations and their shareholders will organize to act in the public good out of pure beneficence. Secondly, we could hope that measures that focus on outcomes versus outputs will be considered more thoroughly by the mainstream anti-hunger organizations, effectively reworking success in food provisioning from "feeding the need" to reducing the need. We could adopt a multicentric economy as Hornborg (2007) suggests, an idea similar to food stamps, the first iteration of food assistance in the U.S. Still, the question remains of what will ultimately inspire action, particularly in those who benefit the least from it? If the anti-hunger system of private charity has been in the making for decades and continues to define itself in relation to inappropriate measures of success, which marginalize smaller-scale entities as irrelevant or unimportant in truly confronting hunger on the scale necessary, then how can this change come about?

Fischer moves beyond an indictment of the contemporary collusion to suggest a series of steps to advance the interests of those on the margins of society. He points to the power of government programs to shift the dominant approach to food security and hunger within the U.S. He draws from a variety of case studies from within and outside the U.S. to demonstrate the myriad approaches that have been successful in alleviating hunger while confronting the underlying power asymmetries between those that have a need and those who provide assistance. Fisher discusses innovations from both within the anti-hunger movement (Chapter 7) and outside of it (Chapter 8) to show what has worked in the past. He builds towards his conclusion, touching on what he refers to as a "new vision for the Anti-Hunger Movement." He shares that he grew increasingly optimistic over the three years it took him to write Big Hunger. At the same time, he notes that the path forward is unclear and likely to be contested in the upcoming iteration of the farm bill.

Overall, Big Hunger: The Unholy Alliance between Corporate America and Anti-Hunger Groups lays out the argument for equity as the fundamental issue in food systems. Fisher reminds the reader that food is never just the material substance that staves off hunger. In this sense, a holistic conceptualization of food security requires considering the security of those throughout the food system, from the recipients of assistance, those who work for less than a living wage in the food sector and retail, and those who have wrested sustenance from the soil. If we take this seriously, then it is possible to move beyond the rhetoric that creates deserving subjects to consider the agency and desires of those who currently have needs. Big Hunger clearly articulates the interwoven nature of food's ability to connect, to touch all aspects of our lives. Big Hunger asks us all to move past Pyrrhic victories in fighting hunger, past objectifying those who need assistance, and past sanitized solutions that are supposedly apolitical. It reaffirms that food systems-from production to distribution to consumption-are always political. Finally, and most notably, Fisher provides ideas and possibilities for activism on multiple fronts to move toward food systems justice, as part of a larger project of social equity.

\section{References}

Hornborg, A. (2007). Learning from the Tiv: Why a Sustainable Economy Would Have to Be "Multicentric." Culture \& Agriculture (now Culture, Agriculture, Food \& Environment), 29(2), 63-69. http://dx.doi.org/10.1525/cag.2007.29.2.63

Parenti, C. (2000). Lockdown America: Police and Prisons in the Age of Crisis. London: Verso. 